\title{
Flavonoids Loaded in Nanocarriers: An Opportunity to Increase Oral Bioavailability and Bioefficacy
}

\author{
Anna Rita Bilia, Benedetta Isacchi, Chiara Righeschi, Clizia Guccione, \\ Maria Camilla Bergonzi \\ Department of Chemistry, University of Florence, Florence, Italy \\ Email: ar.bilia@unifi.it
}

Received 15 April 2014; revised 21 May 2014; accepted 2 June 2014

Copyright @ 2014 by authors and Scientific Research Publishing Inc. This work is licensed under the Creative Commons Attribution International License (CC BY). http://creativecommons.org/licenses/by/4.0/

\begin{abstract}
Flavonoids are among the biggest group of polyphenols, widely distributed in plant-based foods. A plethora of evidence supports the health benefits and value of flavonoids can play in the physiological function treatment and in the prevention of disease particularly in the prevention of degenerative conditions including cancers, cardiovascular and neurodegenerative diseases. Hence, flavonoids represent the active constituents of many dietary supplements and herbal remedies, as well as there is an increasing interest in this class of polyphenols as functional ingredients of beverages, food grains and dairy products. Conversely, various studies have also shown that flavonoids have some drawbacks after oral administration such as stability, bioavailability and bioefficacy. This article reviews the current status of novel nanodelivery systems including nanospheres, nanocaspsules, micro- and nanoemulsions, micelles, solid lipid nanoparticles and nanostructured lipid capsules, successfully developed for overcoming the delivery challenges of flavonoids.
\end{abstract}

\section{Keywords}

Flavonoids, Nanodelivery Systems, Lipid-Based Nanocarriers, Polymer-Based Nanocarriers, Improved Stability, Bioavailability and Bioefficacy

\section{Introduction}

Plants are, virtually, inexhaustible sources of biologically active compounds, which are their defense mechanisms against microorganisms, insects and herbivores. Flavonoids are a large group of polyphenols which occur ubiquitously in plant-based foods and mostly of herbal remedies. Structurally, flavonoids are low-molecular- 
mass phenylchromane derivatives with a basic carbon-based skeleton in C6-C3-C6, a general structural backbone in which the two C6 units (Ring A and Ring B) are of phenolic nature and according to the variations in the heterocyclic ring C, flavonoids can be divided in different classes (Figure 1). The presence of phenyl hydroxyl groups and sugars moieties is very common with a huge number of substitution patterns in both the benzene rings A and $\mathrm{B}$, including methyl and isopentyl units, $O$ - or $C$-glycosyl group(s), galloyl, feruroyl and caffeoyl acids, dimers, oligomers, and polymers [1]. Flavonoids exhibit a wide spectrum of biological activities, either as antioxidants or modulators of cell signaling, and the influence of their metabolism on these properties is key to the evaluation of these potent biomolecules as antioxidants and anti-inflammatory agents, cardioprotectants, and inhibitors of neurodegeneration. Moreover, they have the capacity to inhibit the growth of a wide range of microorganisms and viruses [2]-[4].

Despite the health benefits produced by Flavonoids, the therapeutic outcome is still dependent by the improvement of the pharmacokinetic profile of these compounds after oral administration. Flavonoids have limited water solubility even if they are in the form of glycosides, poor bioavailability, and can be easily modified by environmental factors such as temperature, $\mathrm{pH}$ and light. The mechanisms of gastrointestinal absorption of flavonoids are complex which are poorly absorbed in their natural form in the intestine. It is believed that flavonoids

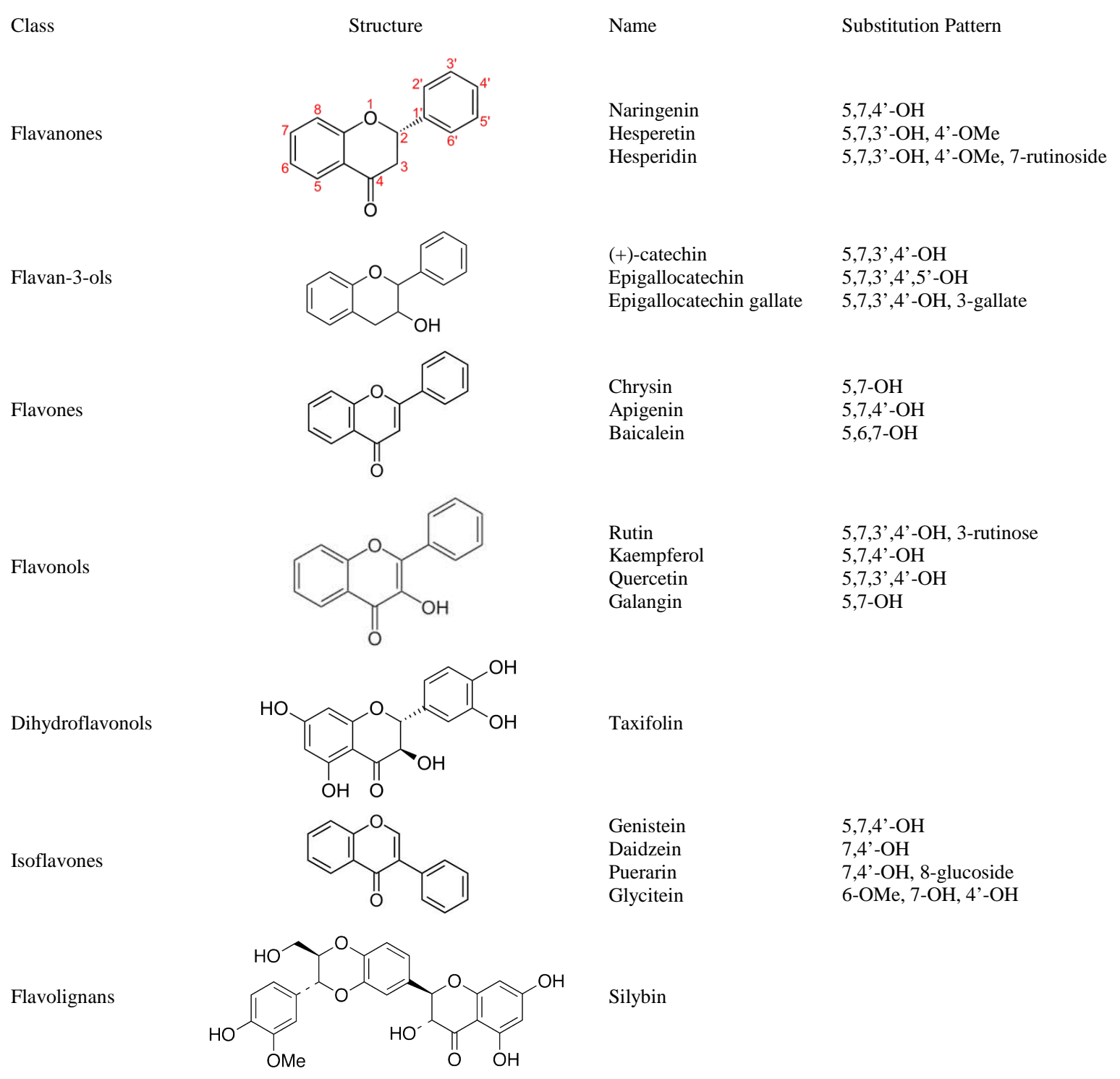

Figure 1. Structures of flavonoids. 
are extensively degraded by intestinal microorganisms and/or enzymes, producing different metabolites. These metabolites, if absorbed, are subjected to the hepatic enzymatic system and new metabolites can be formed varying in bioactivity [5] [6].

After the hydrolysis of the sugar moieties in the small intestine or due to bacterial activity in the colon, aglycones are generated and further metabolized into the metabolism before reaching the systemic circulation. Briefly, numerous factors could play a role in limiting glucuronidated or sulfated form [5] [6]. As a consequence, flavonoids result in poor bioavailability, poor permeability, instability and extensive first-pass bioavailability of flavonoids, such as low water solubility, instability to gastric and colonic $\mathrm{pH}$, metabolism by gut microflora, absorption across the intestinal wall, active efflux mechanism and first-pass metabolic effects. Nanocarriers could be useful to enhance biovailability and bioefficacy of flavonoids because they can increase solubilization potential, alter absorption pathways, and prevent the metabolic degradation within the gastrointestinal tract.

\section{Nanosized Delivery Systems to Increase Oral Bioavailability}

A promising approach to overcome the low oral bioavailability of constituents is the development of nanosized drug carriers (in the size range of 10 - $1000 \mathrm{~nm}$, Figure 2) which can generally be divided into two groups: polymer- and lipid-based systems. Molecular complexes such as cyclodextrin inclusion complexes and molecular associations with lecithin (phytosomes) also represent a valid strategy.

Oral route is the easiest and the most convenient route for both preventive or therapeutic use but flavonoids.

Nanosized delivery systems significantly affect the absorption profile of the loaded molecules because the particle size, shape and surface properties of the nanoparticles play a crucial role in the uptake across the gastrointestinal mucosa. The nanocarriers with particle size of 50 - $300 \mathrm{~nm}$, positive zeta potential and hydrophobic surface were found to have preferential uptake from gastrointestinal tract as compared to their counterparts [7].

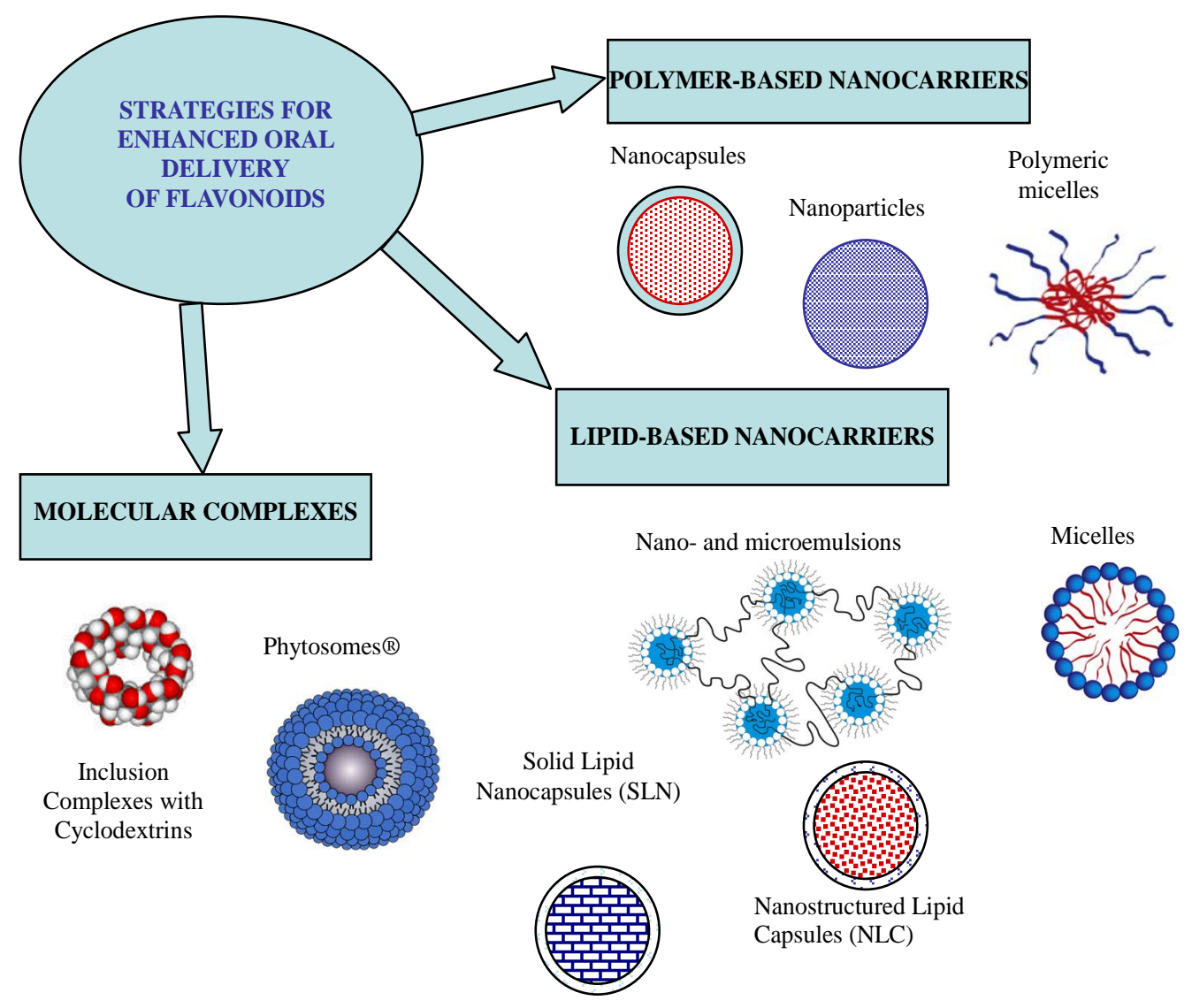

Figure 2. Nanosized delivery systems for oral route. 
Nanocarriers improve the absorption by enterocytes due to increased solubilization and dissolution, mucoadhesion (interaction between the positively charged nanocarrier with negatively charged mucin), tight junction modulation (capability of nanocarriers to interact with the tight junction proteins), receptor-mediated endocytosis and transcytosis, phagocytosis via specialized microfold cells (M cells) of the Peyer's patches and other mucosa associated lymphoid tissues (MALT) and lymphatic absorption via chylomicron uptake mechanism from the enterocytes (mediated by lipase for various lipid based drug delivery systems) [8].

\subsection{Potential Absorption Mechanisms Implemented by Polymer-Based Nanocarriers for Increasing Oral Bioavailability}

Figure 3 depicts various absorption mechanisms by which polymeric nanocarriers improve the oral bioavailability of bioactives.

Various types of polymer based nanocarriers implemented for improving the oral delivery of drugs include nanoparticles and polymeric micelles. The principal advantage of polymeric nanocarriers is their robust structural characteristics imparting very high stability in the gastrointestinal tract. Furthermore, the hydrophobicity and hydrophilicity within the polymeric system can be manipulated to accommodate wide variety of drug molecules [9]. The polymeric nanoparticles tend to show very high degree of sustained release of drug molecules, which could be of special significance for oral delivery to guarantee that no drug is released from the formulation till it reaches systemic circulation thereby bypassing various physiological barriers to oral delivery of difficult-to deliver drugs [10]. Polymeric nanoparticles have the preferential uptake as all nanoparticles, by specialized Peyer's patches (M cells) and the isolated follicles of the gut-associated lymphoid tissue present in the gastrointestinal tract.

After reaching the apical membrane of intestinal epithelial cells, most nanoparticles cross enterocytes via transcellular transport. Through exocytosis they enter the bloodstream or lymphatic vessels. Particles less than $500 \mathrm{~nm}$ in diameter are internalized through both clathrin- and caveolae-mediated endocytosis. Moreover, coating nanoparticles with cationic chitosan or ions protects them from endolysosomal degradation in enterocytes [11].

Polymeric micelles, have been also successfully employed for oral route, considering their various advantages such as superior stability compared to surfactant micelles, enhanced solubilising power, small size [12]. An exhaustive review on the various mechanisms of drug absorption via polymeric micelles from gastrointestinal tract

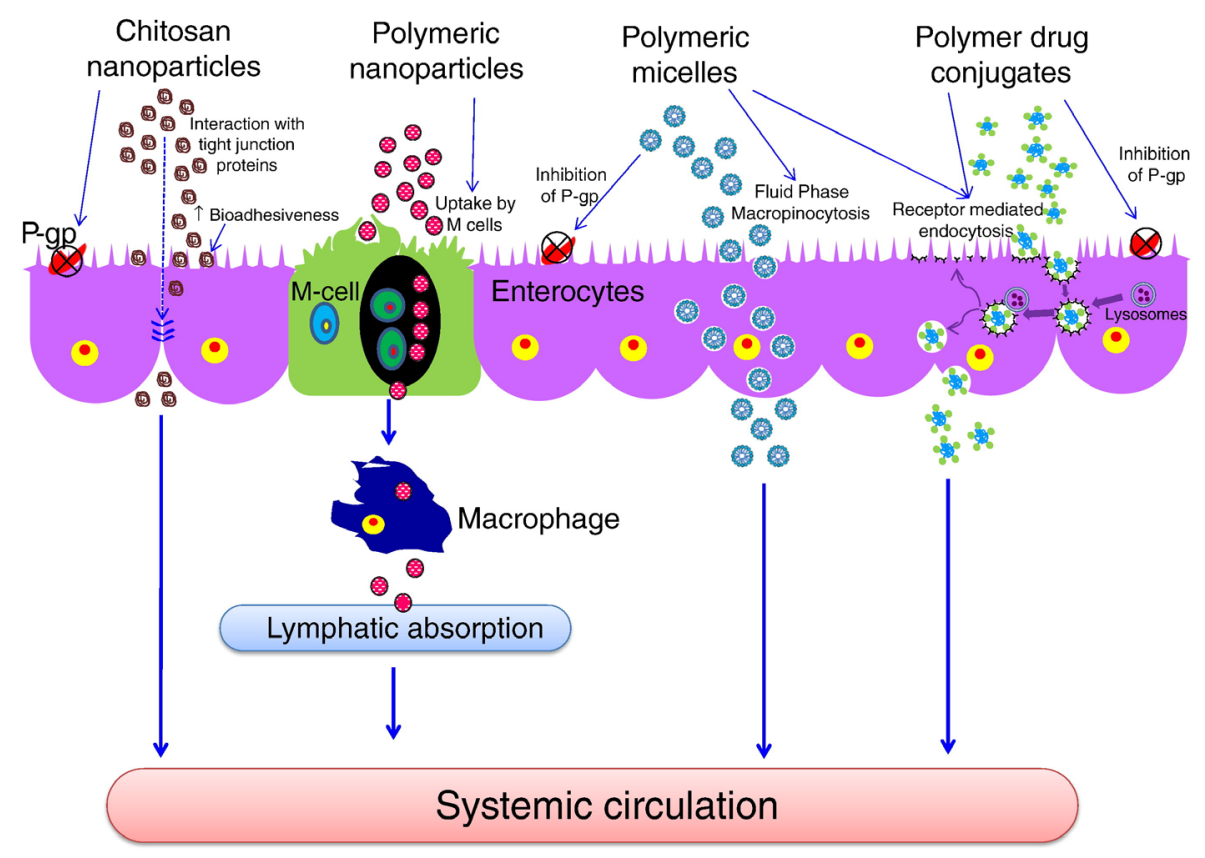

Figure 3. Mechanisms of enhanced drug absorption of polymer-based nanocarriers. Reprinted from [8] with permission. 
is available in literature [13]. Briefly, an alteration in the membrane permeability and an absorption via fluid phase pinocytosis, receptor mediated endocytosis, inhibition of the efflux transporter proteins and mucoadhesion along the gastrointestinal tract represent the major mechanisms of enhanced drug absorption of polymeric micelles.

\subsection{Potential Absorption Mechanisms Implemented by Lipid-Based Nanocarriers for Increasing Oral Bioavailability}

Figure 4 depicts various absorption mechanisms by which lipid nanocarriers improve the oral bioavailability of bioactives. Various types of lipid based nanocarriers have been developed and include microemulsions, nanoemulsions, lipid nanocapsules and nanoparticles, self-emulsifying systems, micelles.

The intraluminal processing of the lipidic excipients has been exhaustively reviewed [14]. Briefly, gastric lipases digest triglycerides in diglycerides and fatty acids in stomach generating an emulsion of lipids wich is exposed to bile salts, cholesterol and phospholipids secreted by gall bladder and pancreatic lipase/co-lipase secreted by pancreas. A further digestion occurs with the formation of stable small sized emulsion droplets.

Acid pathway and the formed micelles will then be absorbed by enterocytes, where it gets converted to the chylomicron upon re-esterification via monoacyl glycerol or phosphatidic subsequent stabilization by phospholipids. Macropinocytosis and endocytosis can also occur.

\section{Flavonoids Loaded in Polymer-Based Nanocarriers}

The carrier materials are natural polymers or synthetic biodegradable high molecular polymers. The latters usually include poly- $\alpha$-cyanoacrylate alkyl esters, polyvinyl alcohol, polylactic acid, polyglycolic acid and polylactic-glycolic acid. The natural ones are usually divided into two classes: polysaccharides and proteins. Polysaccharides include compounds from plant origin (e.g. pectin, cellulose and its derivatives, starch and its derivatives, gum arabic, carrageenan, alginate) and polysaccharides from microbial or animal origin (e.g. xanthan gum, chitosan). Proteins are albumin, gelatine, soy proteins, casein.

Nanoparticles made of polysaccharides, due to their unique properties are promising carriers to deliver and protect the physiological properties of hydrophilic drugs and have been successfully applied as drug-delivery systems [15]. As natural biomaterials, polysaccharides are stable, safe, non-toxic, hydrophilic and biodegradable. In addition, polysaccharides have abundant resources in nature and low cost in their processing.

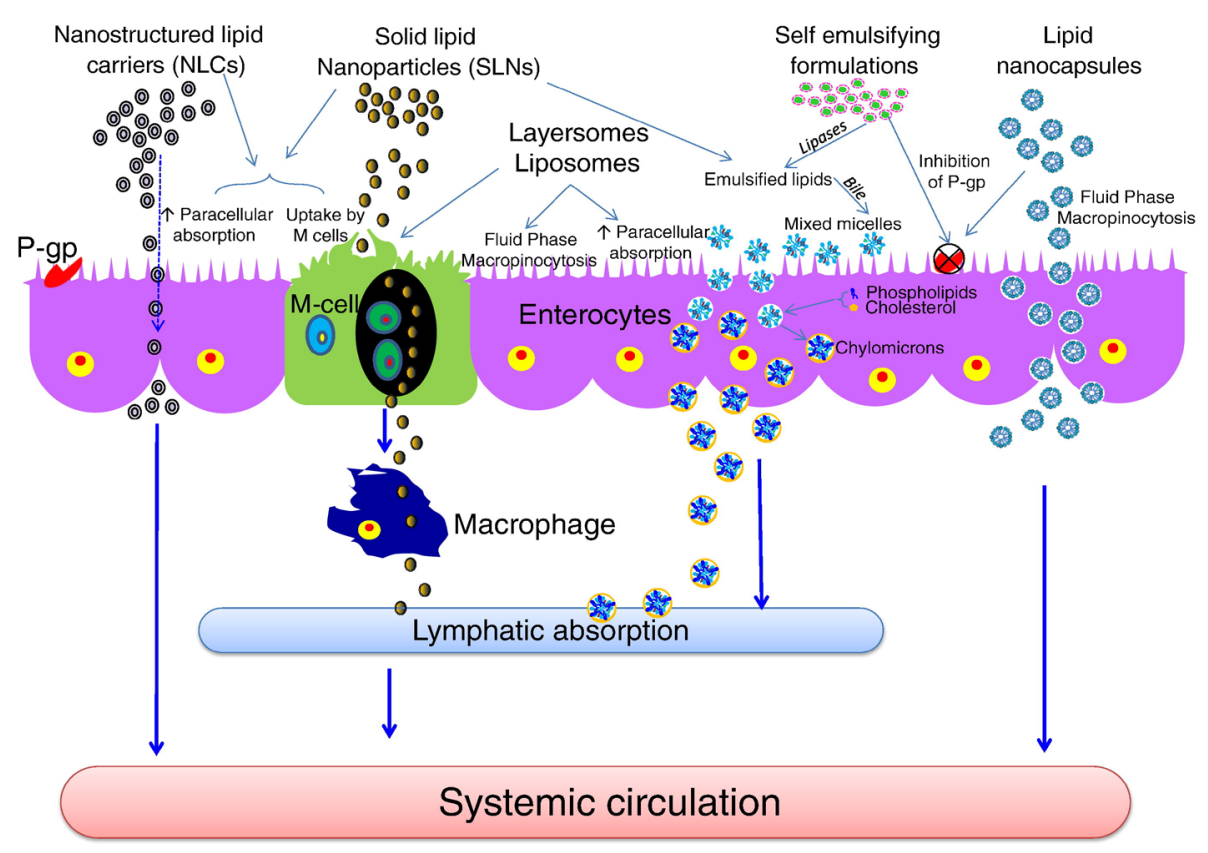

Figure 4. Mechanisms of enhanced drug absorption of lipid-based nanocarriers. Reprinted from [8] with permission. 


\subsection{Polymeric Nanoparticles}

Drugs can be embedded or dissolved in nanoparticles and can also be adsorbed or coupled on the surface. As a consequence, nanoparticles can be broadly divided into reservoir systems like core-shell nanocapsules where the bioactive compound is encapsulated in the core surrounded by polymeric wall and matrix systems wherein the bioactive molecules are embedded in the polymeric matrix. The loading of functional ingredients in the carrier matrix further leads to prevention of degradation. The release of functional ingredients from carriers occurs through one of the following process: dissolution; desorption of the surface-bound/adsorbed functional ingredient; diffusion through the matrix; matrix erosion including enzyme degradation; and a combination of these processes [16].

Diverse examples of successfully polymeric nanocarriers loaded with flavonoids have been reported in the literature.

Catechins, especially those of green tea, have received considerable attention due to their favorable biological properties but their therapeutic potential is limited by their low oral bioavailability $(<5 \%)$ attributed to poor stability and intestinal absorption and a short half life owing to strong systemic clearance [17].

Chitosan nanoparticles significantly $(\mathrm{p}<0.05)$ enhanced intestinal absorption of both $(+)$-catechin and (-)-epigallocatechin gallate. The cumulative amounts transported after encapsulation were significantly ( $\mathrm{p}$ 0.05) higher, i.e. $302.1 \pm 46.1 \mathrm{vs} 206.8 \pm 12.6 \mathrm{ng} / \mathrm{cm}^{2}$ and $102.7 \pm 12.4 \mathrm{vs} 57.9 \pm 7.9 \mathrm{ng} / \mathrm{cm}^{2}$ for catechin and epigallocatechin gallate, respectively. The mechanism by which absorption was enhanced was likely due to stabilization of catechins after encapsulation ( $99.7 \pm 0.7$ vs $94.9 \% \pm 3.8 \%$ and $56.9 \pm 3.0$ vs $1.3 \% \pm 1.7 \%$ of the initial catechin and epigallocatechin gallate concentration respectively) [18].

A study reported the preparation of rutin loaded in chitosan (CH)-tripolyphosphate (TPP) nanoparticles. Optimised particles (4.0:1.0 of CH:TPP mass ratio only) were found to retain rutin in simulated gastric fluids, whereas in conditions which simulated fluids from the small intestine, only $20 \%$ of the entrapped rutin was released and $80 \%$ remained absorbed to the CH:TPP carriers. The particles carried a high positive charge which promoted also mucoadhesion [19].

Polysaccharides nanoparticles based on maltodextrin (hydrolyzed products of starch) and gum Arabic (a hydrocolloid produced by the natural exudation of acacia trees) were loaded with catechins. The particles of $80 \mathrm{~nm}$, negatively charged $(-22 \mathrm{mV})$, had a release triggered by temperature, but not by acidic $\mathrm{pH}$ [20].

A similar formulation was reported for epigallocatechin gallate and coated with lipid layers. including phosphatidylcholine (egg-yolk PC) and stearylamine (SA), a cationic additive. Diameter was $300 \mathrm{~nm}$ and the zeta potential was $56 \pm 5 \mathrm{mV}$. It was observed that lipid coated nanoparticles retain more efficiently the catechins when compared to uncoated particles [21].

Quercetin shows multiple biological activities but it has a poor bioavailability, poor permeability, instability and extensive first pass metabolism before reaching the systemic circulation. PLA nanoparticles loaded ith quercetin were developed with a mean diameter of ca.130 $\pm 30 \mathrm{~nm}$. Antioxidant activity was retained after nanoencapsulation. The in vitro release kinetics under physiological condition show initial burst release followed by slow and sustained release. The complete release and maximum retention of quercetin is 72 and $96 \mathrm{~h}$ respectively [22].

\subsection{Polymeric Micelles}

The hydrophilic shell plays an important role for the in vivo behaviour of the micelles, in particular their steric stabilization and ability to interact with the cells. Quercetin-loaded micelles made from the diblock copolymer, polyethylene glycol (PEG)-derivatized phosphatidylethanolamine (PE) were prepared. Their sizes were 15.4 $18.5 \mathrm{~nm}$ and polydispersity index was ca. 0.250 . Solubility of quercetin by the nanomicelles increased by 110 -fold. The quercetin nanomicelles were stable when tested in simulated gastric $(\mathrm{pH} 1.2)$ and intestinal $(\mathrm{pH}$ 7.4) fluids, and were non-toxic to the Caco-2 cells. The anticancer activity of the nanomicellar formulation increased when tested using the A549 cancer cell line and murine xenograft model [23].

Apigenin has been recognized for many biological properties but it is poorly water soluble molecule (2.16 $\mu \mathrm{g} / \mathrm{mL}$ in water and $0.001-1.63 \mathrm{mg} / \mathrm{mL}$ in high hydrophilic or nonpolar solvents), leading to a poor absorption in gastrointestinal tract.

Polymeric micelles of Pluronic P123 and Solutol HS 15 with an average diameter of $16.9 \mathrm{~nm}$ were prepared. The low CMC $\left(4.23 \times 10^{-5} \mathrm{~mol} / \mathrm{L}\right)$ of the micelles indicated their stability even in a diluted environment. The in 
vitro drug release study showed nearly $84 \%$ of apigenin was released from micelles within $36 \mathrm{~h}$, showing the sustained release property. Cytotoxicity of apigenin loaded polymeric micelles against HepG2 and MCF-7 cancer cell in vitro was remarkably higher than that of the free drug [24].

\section{Flavonoids Loaded in Lipid-Based Nanocarriers}

Lipid based nanosystems include micelles, solid lipid nanoparticles (SLN), nanostructured lipid carriers (NLC), nanoemulsions and microemulsions. Lipids and surfactant active agents are generally selected from a big plethora of edible constituents and Generally Recognized As Safe (GRAS) approved compounds. Their size can range from around $10 \mathrm{~nm}$ for micelles to hundreds of nanometres for the other systems. Stabilization which is the basic requirement for formation of colloidal systems could be achieved either by surface charge (electrostatic stabilization); surface adsorption of a layer of surfactant or polymer (steric stabilization) or a combination of both surface charge and steric adsorption (electrosteric stabilization).

\subsection{Micelles}

Micelles are colloidal assemblies of amphiphilic molecules that occur at the critical micelle concentration (CMC). In polar media such as water, the hydrophobic part is the core while the polar head groups tend to locate at the solvent interface taking up several forms, depending on the conditions and composition of the system, such as distorted spheres, disks, or rods. Bioactive compound can be solubilized in molecular state and localized either in the core or the palisade of micelles (depending on its polarity) and a equilibrium partition of compound in micelles and aqueous bulk phase is established [25]. When a combination of hydrophobic (HLB value < 10) and hydrophilic surfactants (HLB value $>10$ ) is used we can also form a mixed micellar system which can be used as delivery system [26].

Micellar systems have several attributes to be considered as effective delivery systems: small size (typically < $20 \mathrm{~nm}$ ); thermodynamic stability (spontaneous formation above CMC) and colloidal stability [26].

Rutin has various biological effects, attributed partly to its ability to scavenge free radicals which can be related to the nature of micellar media. As a consequence, the interaction of rutin with the radical DPPH (2,2-diphenyl-1 picrylhydrazyl) in presence of cationic (CTAB, TTAB, DTAB), non-ionic (Brij78, Brij58, Brij35), anionic (SDS) and mixed surfactant systems (CTAB-Brij58, DTAB-Brij35, SDS-Brij35) has been investigated. The results show that the solubilization capacity of various single surfactant systems for rutin followed the order: cationics $>$ non-ionics $>$ anionic. The radical scavenging activity of rutin in the solubilized form was higher within ionic micelles than in non-ionic micelles. Mixed surfactant systems exhibited better solubilization capacity than single component systems indicating a favorable mixing effect on solubilization of rutin as well as a similar rutin interaction with the radical DPPH [27].

\subsection{Microemulsions, Nanoemulsions and Self-Microemulsifying Drug Delivery Systems}

Microemulsion also known as swollen micelle, typically contains droplets with radii between the range of 2 to $100 \mathrm{~nm}$. They are thermodynamically stable and formed spontaneously. Fabricating nanoemulsions and microemulsions usually requires fairly similar ingredients: an oil phase, an aqueous phase, a surface active agent and probably a co-surfactant [28]. Microemulsions require special oils and synthetic surfactants, very high concentration of surfactant and precise production approach. Moreover they are prone to disintegration upon the changes of environmental conditions (e.g. composition and temperature).

Nanoemulsions, often also called miniemulsions, are emulsions consisting of droplets which are significantly (by a factor of 10 or so) smaller than the droplets present in ordinary emulsions. They are thermodynamically unstable systems exhibiting, however, high kinetic stability which can be for several years. Moreover their low viscosity and optical transparency make them very attractive delivery systems for example, in the pharmaceutical field as drug delivery or other application area. The droplet is typically stabilized by a layer that consists of a mixture of surfactant and co-surfactant [28].

Although both nanoemulsions and microemulsions show long-term stability (due to a different mechanism), microemulsions are much more sensitive to envionmental changes, such as temperature, ionic strength, composition (adding/removing molecules to/from the aqueous continuous phase). A drawback when comparing to nanoemulsions, is that microemulsion formation requires the use of relatively large amounts of surfactant, i.e., 
their loading capacity is significantly lower than this of comparable nanoemulsion delivery systems, especially when using triglycerides as the dispersed oil phase [28].

A further and very successful approach to improve the solubility, chemical stability, and oral bioavailability of poorly water soluble molecules is self-microemulsifying drug delivery systems (SMEDDS). They are defined as isotropic mixtures of oil, surfactant, cosurfactant and drug, which form oil-in water microemulsion with droplet size less than $100 \mathrm{~nm}$ when exposed to aqueous media with gentle agitation or motility of gastrointestinal tract [29].

Quercetin-loaded microemulsion (oil-in-water microemulsion content 0.02:0.2:1 of lecithin:castor oil:Solutol $\mathrm{HS}^{\circledR}{ }^{\circledR}$ ) has been developed and compared with quercetin in vivo. Only quercetin-loaded microemulsion inhibited in a dose-dependent way, the eosinophil recruitment to the bronchoalveolar lavage fluid and significantly reduced both IL-5 and IL-4 levels, the nuclear transcription factor kappa B activation, P-selectin expression and the mucus production in the lung. Quercetin-loaded microemulsion exhibited pronounced anti-inflammatory properties in a murine model of airways allergic inflammation [30].

Puerarin, the characteristic flavonoid of the root of Pueraria lobata, an herbal drug used in traditional Chinese Medicine with many beneficial properties is practically water insoluble with a low bioavailability.

A study [31] has reported the preparation of self-microemulsifying drug delivery systems (SMEDDS) in sustained release pellets to enhance the oral bioavailability of puerarin. Castor oil was used as the oil phase, Cremophor ${ }^{\circledR}$ EL as the emulsifier, and 1,2-propanediol as the co-emulsifier. The mean particle size was $50 \pm 8 \mathrm{~nm}$. The pharmacokinetic and bioavailability of the puerarin-SMEDDS ustained-release pellets and puerarin tablets were compared in beagle dogs. The absolute bioavailability of the puerarin-SMEDDS was enhanced by 2.6-fold compared with that of the puerarin tablet. The relative bioavailability of the SMEDDS pellets was $259.7 \%$ compared with the conventional tablet group. The results demonstrated that the puerarin-SMEDDS pellets had a sustained-release effect, and could remarkably improve the oral bioavailability of puerarin [31].

Polymethoxyflavones including 5,7 dimethoxyflavone, 5,7,4'-trimethoxyflavone, and 3,5,7,3',4'-pentamethoxyflavone are the characteristic constituents of Kaempferia parviflora, widely used as herbal medicine for centuries in Asia for diverse biological properties. Polymethoxyflavones have poor water solubility and low oral bioavailability (1\% - 4\%).

Accordingly, SMEDDS were developed as follows: polyoxyethylene castor oil (53.3\%), propylene glycol (26.7\%), and triglyceride of coconut oil (20\%). The oral bioavailability values of SMEDDS formulations were higher than those of plant extracts (25.38-, 42.00-, and 26.01-fold for 3,5,7,3',4'-pentamethoxyflavone, 5,7,4'trimethoxyflavone, and 5,7 dimethoxyflavone, respectively) [32].

Silybin, a characteristic flavolignan from fruits of milk thistle (Silybum marianum (L.) Gaertn), has always been used to treat liver, spleen and gallbladder disorders. However, the clinical efficacy of silybin is limited by its poor water solubility $(0.4 \mathrm{mg} / \mathrm{mL})$, which results in poor oral absorption and bioavailability. A formulation consisting of silybin, Labrafac CC, Cremophor RH40, Labrasol and 5\% HPMC enhanced oral bioavailability of silybin [33]. The in vivo study indicated that the area under the concentration-time curve (AUC0 $\rightarrow 12 \mathrm{~h}$ ) of the silybin-preparation increased by nearly 3-fold more than those of the conventional self-emulsifying drug delivery systems without the presence of HPMC at a drug dose of $533 \mathrm{mg} / \mathrm{kg}$ [33].

Another study investigated SMEDDS loaded with silymarin (the total extract, principally silybin). It consisted of $10 \%(\mathrm{w} / \mathrm{w})$ of ethyl linoleate, $30 \%$ of Cremophor EL, and $60 \%$ of ethyl alcohol. The bioavailability was enhanced about 2.2-fold compared with the unformulated extract in fasted dogs [34].

Also quercetin has been formulated into SMEDDS to improve its oral bioavailability and antioxidant potential. The formulation was optimized using 40:40:20 w/w of Capmul MCM:QT (19:1)/Tween20/ethanol. The formulation showed a rapid internalization within $1 \mathrm{~h}$ of incubation with Caco-2 cells and a significant increase in cellular uptake by 23.75-fold in comparison with free quercetin cultured with Caco-2 cells. Five-fold enhancement in oral bioavailability compared to free quercetin suspension was found [35].

Baicalein, the characteristic flavone of the root of Scutellaria baicalensis, has multiple biological activities but its poorly water solubility is limiting its bioefficacy. Optimized SMEDDS formulations for baicalein were Cremophor RH40 (53.57\%) as surfactant, Transcutol P (21.43\%) as cosurfactant, and caprylic capric triglyceride (25\%) as oil. The drug release rate of SMEDDS was significantly higher than that of the baicalein suspension. The in vivo studies showed that the absorption of baicalein from SMEDDS resulted in about $200.7 \%$ increase in relative bioavailability compared with that of the baicalein suspension [36]. 


\subsection{Solid Lipid Nanoparticles}

Solid lipid nanoparticles (SLN) refer to nanoscale size particles prepared using lipids that remain solid at room temperature (or/and body temperature). The lipid component may comprise of a broad range of lipid and lipid-like molecules such as triacylglycerols or waxes.

The diameter of such lipid particles can be also quite small, i.e. in the range between $50 \mathrm{~nm}$ and $1 \mu \mathrm{m}$. Active ingredients can be solubilized homogeneously either in the core of the SLNs or in the outside part. The advantages of SLNs are an increased chemical protection, less leakage and sustained release [37].

Quercetin-loaded SLN were $155.3 \mathrm{~nm}$, the average drug entrapment efficiency, drug loading and zeta potential were $91.1 \%, 13.2 \%$ and $-32.2 \mathrm{mV}$, respectively. The relative bioavailability of quercetin loaded in SLNs compared to quercetin suspension was $571.4 \%$ [38].

SLNs were also developed with puerarin, a hardly water-soluble flavonoid with protective effects on cardioand cerebrovascular diseases. SLNs with average particle size of $160 \mathrm{~nm}$ and a zeta potential of $-35.43 \mathrm{mV}$ were formulated using monostearin, soya lecithin and poloxamer 188. The Cmax value of puerarin after the administration of SLNs was significantly higher than that obtained with puerarin suspension $(0.33 \pm 0.05 \mu \mathrm{g} / \mathrm{mL}$ vs. $0.16 \pm 0.06 \mu \mathrm{g} / \mathrm{mL}, \mathrm{P}<0.01)$. The Tmax value after the administration of the SLNs was significantly shorter than that after puerarin suspension administration $(40 \pm 0$ min vs. $110 \pm 15.49 \mathrm{~min}, \mathrm{P}<0.01)$. The AUC0 $\rightarrow \mathrm{t}$ values of puerarin were $0.80 \pm 0.23 \mathrm{mg} \cdot \mathrm{h} / \mathrm{L}$, and $2.48 \pm 0.30 \mathrm{mg} \cdot \mathrm{h} / \mathrm{L}$ after administration of the puerarin suspension and SLNs loaded with puerarin, respectively. The relative biovailability of puerarin loaded in SLN improved more than 3 fold [39].

\subsection{Nanostructured Lipid Carriers}

The process of full-crystallization or recrystallization of fat reduces the drug solubility, leads to drug expulsion from the lipid nanoparticles especially when the drug concentration in the formulation is too high. Majority of thedrugs have higher solubility in a liquid lipid rather than a solid lipid. Nanostructured Lipid Carriers (NLC) are a modified SLN in which the lipidic phase contain both solid (fat) and liquid (oil) lipids at room temperature [40]. The lipid blend in NLC has slower polymorphic transition and low crystallinity index. Along with existing oil in the NLC-core, the spherical shape of the particle may account for these improving properties [40]. It therefore seems that NLC dispel the SLN drawbacks and possess the advantages of SLN and thereupon other lipid nanocarriers. Thus, NLC may increase encapsulation efficiency, drug loading and physical stability and it seems to be a valuable option for improving the chemical stability, bioavailability and controlled release of functional lipophilic compounds.

Quercetin has been loaded in cationic NLC made of solid lipids (glycerol monostearate)/liquid lipids (medim chain triglycerides) ratio was $4: 1$, concentration of lecithin was $3 \%$, concentration of didodecyldimethylammonium bromide was $1 \%$ and the quercetin $5 \%$. The average particle size was $126.6 \mathrm{~nm}$, a zeta potential of +40.5 $\mathrm{mV}$ and $89.3 \%$ entrapment efficiency. The formulation performed slower release compared with quercetin suspension in vitro, and it showed higher AUC and Cmax values in lung, liver and kidney compared with control group after oral administration of the formulation compared with quercetin suspension [41].

Hesperetin is a flavanone abundantly found in Citrus fruits has diverse valuable benefits, its poor solubility in water (20 ppm or less) and bitter taste represent considerable obstacles to its use for food fortification. A recent study reports the development of both SLN and NLC [42]. SLN were prepared using different ratios of glycerol monostearate or stearic acid, glyceryl behenate $\left(\mathrm{Compritol}^{\circledR}{ }^{888}\right.$ ) and Tween 80 . For NLC formulations $15 \%$ of the solid lipid was replaced by oil, i.e. Estasan (caprylic/capric triglyceride) and oleic acid.

NLC formulations showed smaller size in comparison to SLN formulations and hesperetin encapsulation load ranged from $3.00 \%$ to $6.28 \%$.

NLC formulation containing glycerol monostearate and $0.064 \%$ hesperetin had better properties in term of size, zeta potential, encapsulation efficiency, stability and hesperetin release [42].

In a further study [43], different polymers (chitosan, alginate and low methoxypectin) were employed and evaluated in their behavior to mask bitterness, inhibit colour change and enhance hesperitin solubility.

Among different nanoparticles, those containing $0.5 \%$ alginate-chitosan polymers had better protection against acidic conditions which resulted about $11 \%$ of released hesperetin after $2 \mathrm{~h}$. Pectin was not able to protect hesperetin against acidic conditions probably due to its incapability to form a film on the surface of NLC [43]. 


\section{Molecular Complexes}

A simple strategy to deliver active ingredients is by physically complexing them with other molecules in order to have a better solubility profile and/or an increase in the chemical stability of the complexed system. In this context a molecular complex is referring to the physical association between a host and a guest (active ingredient) molecule.

\subsection{Cyclodextrins Inclusion Complexes}

Cyclodextrins are natural macrocyclic oligosaccharides well known for having toroid-shaped structures with rigid lipophilic cavities and a hydrophilic outer surface insuring good dissolution of the complex in an aqueous environment. They are able to enclose highly hydrophobic molecules inside their hydrophobic cavity, constituting a true molecular encapsulation [44].

The major advantages of the use of CD-complexation are protection of the active ingredients against oxidation, control of light induced reactions, of decomposition and thermal decomposition, of loss by evaporation and sublimation, elimination or reduction of undesired tastes/odors, prevention of gastric-intestinal irritation (mainly due to anti-inflammatory drugs) or ocular disturbances, avoidance of drug-drug or drug-additive interactions, and even conversion of oils and liquid molecules into microcrystalline or amorphous powders. Reduction of microbiological contamination and hygroscopicity are also reported. Moreover, formation of inclusion complex (IC) increases the guest's in vivo bioavailability and bioefficacy [44]. There are three main types of natural CDs: $\alpha$-, $\beta$ - and $\gamma$-cyclodextrins, corresponding to 6,7 and 8 glucopyranose units linked by $\alpha-(1,4)$ bonds, respectively (Figure 5). The dimensions of the internal cavity are $0.5-0.8 \mathrm{~nm}$ and are crucial for the 'encapsulation' of guest molecules [44].

Besides natural cyclodextrins, a growing number of semi-synthetic derivatives and co-polymers has been developed and because their better solubility in water, modulation of the release rate, the inclusion capacity and side effects of guest molecules. Based on the literature data, especially $\beta$-cyclodextrin and its derivatives, represent good carriers to improve water solubility and stability of flavonoids, increasing their antioxidant activity, bioavailability and bioefficacy. The $\beta$-CD derivatives are: hydroxyproyl- $\beta$-cyclodextrin (HP- $\beta$-CD), methyl- $\beta$-cyclodextrin (M- $\beta$-CD), dimethyl- $\beta$-cyclodextrin (DM- $\beta$-CD), trimethyl- $\beta$-cyclodextrin (TM- $\beta$-CD), solphobutylether- $\beta$-cyclodextrin (SBE- $\beta$-CD), glucosyl- $\beta$-cyclodextrin (G2- $\beta$-CD).

The solubility profile of epigallocatechin after encapsulation with $\beta$-CD, HP- $\beta$-CD and DM- $\beta$-CD has been recently investigated [45]. DM- $\beta$-CD was the most suitable CD for the complexation and to increase solubility of epigallocatechin.

The encapsulation of rutin with $\alpha$-CD, $\beta$-CD, HP- $\beta$-CD and DM- $\beta$-CD was described by different authors in order to improve its solubility. The enhancement of the oral availability by the capsulation of rutin by HP- $\beta$-CD was proved by Miyake and co-workers after administration of the ICs to beagle dogs [46]. The stability of rutin

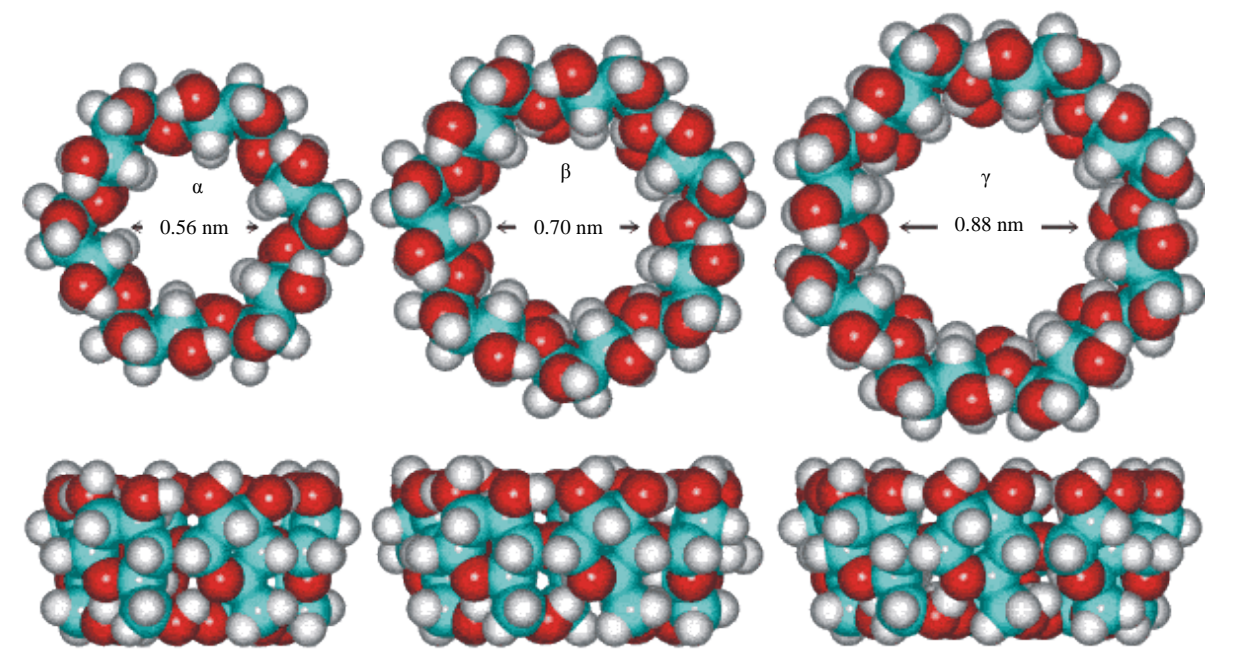

Figure 5. Structure of natural cyclodextrins. 
was improved by complexation with HP- $\gamma$-CD or HP- $\beta$-CD. The HP groups enhanced the interactions stability of the CD with rutin and the analysis of NMR showed that the A ring was inside the cavity of HP- $\beta$-CD [47].

Chrysin IC with $\beta$-CD, HP- $\beta$-CD, DM- $\beta$-CD had stoichiometry 1:1 and HP- $\beta$-CD complex had the higher K $\left(1855 \mathrm{M}^{-1}\right)$. The interaction between the chrysin and the CDs occurs by the A-ring of the flavones [48].

The $\beta$-CD, SBE- $\beta$-CD and HP- $\beta$-CD were also used to improve solubility and photostability of quercetin by several authors. The CD derivatives were more efficient on the solubilization of quercetin than the natural CD and showed better antioxidant activity. Temperature is a crucial parameter on IC formation [49] [50].

Carlotti et al. (2010) also reduced the photodegradation ratio of the quercetin by its complexation with $\mathrm{M}-\beta$-CD [51].

The interactions of galangin, kaempferol and quercetin with $\alpha, \beta$ - and $\gamma$-CDs were investigated by Bergonzi and coworkers [52]. The host-guest interactions were studied both in solution and in the solid state. The increased solubility of quercetin and kaempferol in the presence of $\beta$-CD was assessed. Multidimensional NMR experiments in DMSO and water were consistent with dynamic binding processes, dominated by insertion of the $\mathrm{B}$ ring into the wider rim of the CD cavity. In addition, some smaller interactions with protons of ring $\mathrm{A}$ and the protons inside the $\mathrm{CD}$ cavity were found, probably according to a dynamic binding between flavonol and $\mathrm{CD}$ systems.

IC formation of kaempferol with $\beta$-CD derivatives such as HP- $\beta$-CD, DM- $\beta$-CD and G2- $\beta$-CD has also been reported. NMR experiments provided data indicating that the B-ring of kaempferol is immersed in the apolar cavity with the A- and C-ring protruding from the wider rim for the cyclodextrins. The complexes behave as better antioxidants than kaempferol alone [53].

The formation of IC between naringenin and $\beta$-CD and its derivatives (HP- $\beta$-CD, DM- $\beta$-CD, M- $\beta$-CD and TM- $\beta$-CD) was analysed by several authors. For all the tested CDs the stoichiometry of the IC was $1: 1$, and the HP- $\beta$-CD was the CD with higher stability constant [54]. It was demonstrated that the water solubility and thermal stability of this flavonoid was improved when encapsulated by $\beta$-CD, DM- $\beta$-CD or TM- $\beta$-CD. Based on NMR analysis, they assumed that the C-ring of naringenin was interacting with the CDs' cavity [55]. The biological effect of the IC naringenin/HP- $\beta$-CD was also described. It was proved that the solubility of the flavonoid was increased 400 times when complexed with the HP- $\beta$-CD; moreover the naringenin transport across the model of the gut epithelium (Caco-2 cells) was also enhanced of 11 -fold as well as its plasma concentration. Complexation with HP- $\beta$-CD increased the oral bioavailability of naringenin of 7.4-fold [54].

It has been investigated the effect of the $\beta$-CD and HP- $\beta$-CD on the solubility of hesperetin and its glycoside hesperidin [56] [57]. ICs showed an improvement on the solubility and chemical stability [57]. The better complexation was observed with HP- $\beta$-CD and hesperetin, based on the higher $\mathrm{K}$ values $\left(21,000 \mathrm{M}^{-1}\right)$ when com-

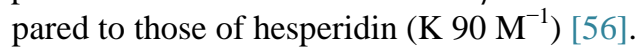

Native CDs and HP- $\beta$-CD were investigated for their ability to form an IC with taxifolin. $\beta$-CD showed better capacity to interact with this dihydroflavanonol [58].

The IC formation between genistein and $\beta$-CD, $\beta$-CD, HP- $\beta$-CD and RM- $\beta$-CD has been studied. Genistein was capable of interacting with all the CDs, but the CD derivatives induced a higher effect on the solubility of the compounds. Genistein ability to cross biological membranes was also improved by the encapsulation with the CDs [59]. $\beta$-CD and HP- $\beta$-CD IC formation was investigated with a mixture of daidzein, genistein and glycitein [60]. All the isoflavones showed the highest affinity with HP- $\beta$-CD and the interaction between the CD and the bioactive molecules occur by insertion of the B-ring into the CD cavity [60].

\subsection{Phytosomes ${ }^{\circledR}$}

Several herbal extracts or single constituents from the diverse classes of metabolites (principally polyphenols and terpenoids) are marketed in the form of Phytosome ${ }^{\circledR}$, a patented technology made of a special molecular complex with naturally occurring phospholipid molecules, mainly phosphatidylcholine, in order to enhance absorption and bioavailability of the constituents. Phytosome ${ }^{\circledR}$ is the result of a molecular complex between phosphatidylcholine and the plant components (1:1 or a 2:1), involving chemical bonds [61] [62]. Phytosomes ${ }^{\circledR}$ are highly compatible with the human physiological system and more bioavailable as compared to conventional herbal extracts or single constituents owing to their enhanced capacity to cross the lipidic enterocyte cell membrane and finally reaching the systemic circulation. They also help in reducing their dose and increasing their duration of action because of the sustained drug release pattern with them [61] [62]. Flavonoids represent good 
candidates for this formulation approach.

The pharmacokinetic profile of quercetin, kaempferol and isorhamnetin present in Ginkgo biloba extract after oral administration in rats by formulating phytosome has been evaluated. $\mathrm{C}_{\max }$ of quercetin increased from 179.21 to 724.89 , from 180.23 to 323.56 in case of kaempferol and from 195.96 to 672.29 in case of isorhamnetin. The AUC0s of quercetin, kaempferol and isorhamnetin of the G. biloba phospholipid complex relative to the G. biloba extract were found to be increased by 2.42, 1.95 and 2.35 times respectively. The Tmax of all the three constituents was found to be shorter in case of the phospholipid complex when compared with the Tmax of crude extract. The results also demonstrated a large increase in bioavailability of the extract in its phospholipid complexed form [63].

Silybin phytosome was the first commercially available product based on Phytosome ${ }^{\circledR}$ technology, and showed significant liver protection and enhanced bioavailability of silybin [64]. In the phytosome silybin binds with the phospholipid via its polar end, and the nonpolar portion of the phospholipid remains free, enhancing the lipid solubility of the complex. These lipophilicity-improved flavanolignan-phospholipid complexes have increased oral bioavailability and, consequently, enhanced pharmacological activity. In a comparative pharmacokinetic study using an equimolar dose of silybin and its complex, the plasma Cmax of silybin after four hours was $<35 \mathrm{ng} / \mathrm{ml}$, whereas for the silybin complex, it was $112 \mathrm{ng} / \mathrm{ml}$ [65]. A phytosome made of a commercial green tea extract, principally represented by (-)-epigallocatechin 3-O-gallate, enhanced the absorption of catechins, when compared with free-form green tea catechins. The peak concentration at two hours was more than doubled with the phytosome compared with the simple commercial extract [66].

The water solubility of quercetin was improved by 12 folds (from $3.44 \mu \mathrm{g} / \mathrm{ml}$ to $36.81 \mu \mathrm{g} / \mathrm{ml}$ ) in the phytosome formulation. The antioxidant activity, was not affected by the complexation [67].

\section{Concluding Remarks}

Flavonoids have a low bioavailability but an enormous health potential which should be explored through some value added drug delivery systems. Water solubility and gastric stability are the major limiting factors for flavonoids to pass the biological membrane and to be absorbed systematically following oral administration. As a consequence, many excellent bioactivities in vitro demonstrate less or no in vivo actions. Flavonoids when administered through nano-sized delivery systems show much better stability and absorption profile. Consequently, the activity becomes enhanced, more detectable and prolonged. In comparison to micro-delivery systems, the nanocarriers have some advantages: they are more stable, provide more surface area and have the potential to enhance the bioavailability by increasing the absorption from enterocytes, by receptor-mediated endocytosis and transcytosis, phagocytosis via specialized microfold cells. Finally, the nano-delivery systems improve controlled release of the encapsulated flavonoids. All the nanocarriers reported in this review are made of Generally Recognized As Safe (GRAS) approved compounds and can represent driving formulating carriers for innovative and more effective formulations of functional foods, dietary supplements and herbal medicinal products.

\section{References}

[1] Harborne, J.B. and Williams, C.A. (2000) Advances in Flavonoid Research Since 1992. Phytochemistry, 55, 481-504. http://dx.doi.org/10.1016/S0031-9422(00)00235-1

[2] Ross, J.A. and Kasum, C.M. (2002) Dietary Flavonoids: Bioavailability, Metabolic Effects, and Safety. Annual Review of Nutrition, 22, 19-34. http://dx.doi.org/10.1146/annurev.nutr.22.111401.144957

[3] Yao, L.H., Jiang, Y.M., Shi, J., Tomás-Barberán, F.A., Datta, N., Singanusong, R. and Chen, S.S. (2004) Flavonoids in Food and Their Health Benefits. Plant Foods for Human Nutrition, 59, 113-122. http://dx.doi.org/10.1007/s11130-004-0049-7

[4] Heim, K.E., Tagliaferro, A.R. and Bobilya, D.J. (2002) Flavonoid Antioxidants: Chemistry, Metabolism and Structure-Activity Relationships. The Journal of Nutritional Biochemistry, 13, 572-584. http://dx.doi.org/10.1016/S0955-2863(02)00208-5

[5] Manach, C., Williamson, G., Morand, C., Scalbert, A. and Rémésy, C. (2005) Bioavailability and Bioefficacy of Polyphenols In Humans. I. Review of 97 Bioavailability Studies. American Journal of Clinical Nutrition, 81, $230-242$.

[6] Stahl, W., van den Berg, H., Arthur, J., Bast, A., Dainty, J., Faulks, R.M., Gärtner, C., Haenen, G., Hollman, P., Holst, B., Kelly, F.J., Polidori, M.C., Rice-Evans, C., Southon, S., van Vliet, T., Viña-Ribes, J., Williamson, G. and Astley, S.B. (2002) Bioavailability and Metabolism. Molecular Aspects of Medicine, 23, 39-100. 
http://dx.doi.org/10.1016/S0098-2997(02)00016-X

[7] Roger, E., Lagarce, F., Garcion, E. and Benoit, J.-P. (2010) Biopharmaceutical Parameters to Consider in Order to Alter the Fate of Nanocarriers after Oral Delivery. Nanomedicine, 5, 287-306. http://dx.doi.org/10.2217/nnm.09.110

[8] Thanki, K., Gangwal, R.L.P., Sangamwar, A.T. and Jain, S. (2013) Oral Delivery of Anticancer Drugs: Challenges and Opportunities” Journal of Controlled Release, 170, 15-40. http://dx.doi.org/10.1016/j.jconrel.2013.04.020

[9] Plapied, L., Duhem, N., des Rieux, A. and Préat, V. (2011) Fate of Polymeric Nanocarriers for Oral Drug Delivery. Current Opinion in Colloid \& Interface Science, 16, 228-237. http://dx.doi.org/10.1016/j.cocis.2010.12.005

[10] Brannon-Peppas, L. (1995) Recent Advances on the Use of Biodegradable Microparticles and Nanoparticles in Controlled Drug Delivery. International Journal of Pharmaceutics, 116, 1-9.

http://dx.doi.org/10.1016/0378-5173(94)00324-X

[11] Rejman, J., Oberle, V., Zuhorn, I.S. and Hoekstra, D. (2004) Size-Dependent Internalization of Particles via the Pathways of Clathrin- and Caveolae-Mediated Endocytosis. Biochemical Journal, 377, 159. http://dx.doi.org/10.1042/BJ20031253

[12] Jones, M.C. and Leroux, J.C. (1999) Polymeric Micelles-A New Generation of Colloidal Drug Carriers. European Journal of Pharmaceutics and Biopharmaceutics, 48, 101-111. http://dx.doi.org/10.1016/S0939-6411(99)00039-9

[13] Gaucher, G., Satturwar, P., Jones, M.-C., Furtos, A. and Leroux, J.-C. (2010) Polymeric Micelles for Oral Drug Delivery. European Journal of Pharmaceutics and Biopharmaceutics, 76, 147-158. http://dx.doi.org/10.1016/j.ejpb.2010.06.007

[14] Porter, C.J.H., Pouton, C.W., Cuine, J.F. and Charman, W.N. (2008) Enhancing Intestinal Drug Solubilisation Using Lipid-Based Delivery Systems. Advanced Drug Delivery Reviews, 60, 673-691. http://dx.doi.org/10.1016/j.addr.2007.10.014

[15] Liu, Z., Jiao, Y., Wang, Y., Zhou, C. and Zhang, Z. (2008) Polysaccharides-Based Nanoparticles as Drug Delivery Systems. Advanced Drug Delivery Reviews, 60, 1650-1662. http://dx.doi.org/10.1016/j.addr.2008.09.001

[16] Soppimath, K.S., Aminabhavi, T.M., Kulkarni, A.R. and Rudzinski, W.E. (2001) Biodegradable Polymeric Nanoparticles as Drug Delivery Devices. Journal of Control Release, 70, 1-20. http://dx.doi.org/10.1016/S0168-3659(00)00339-4

[17] Zhang, L. and Kosaraju, S.L. (2007) Biopolymeric Delivery System for Controlled Release of Polyphenolic Antioxidants. European Polymer Journal, 43, 2956-2966. http://dx.doi.org/10.1016/j.eurpolymj.2007.04.033

[18] Dube, A., Nicolazzo, J.A. and Larson, I. (2010) Chitosan Nanoparticles Enhance the Intestinal Absorption of the Green Tea Catechins (+)-Catechin and (-)-Epigallocatechin Gallate. European Journal of Pharmaceutical Sciences, 41, 219225. http://dx.doi.org/10.1016/j.ejps.2010.06.010

[19] Konecsni, K., Low, N.H. and Nickerson, M.T. (2012) Chitosan-Tripolyphosphate Submicron Particles as the Carrier of Entrapped Rutin. Food Chemistry, 134, 1775-1779. http://dx.doi.org/10.1016/j.foodchem.2012.03.070

[20] Ferreira, I., Rocha, S. and Coelho, M. (2007) Encapsulation of Antioxidants by Spraydrying. Chemical Engineering Transactions, 11, 713-717.

[21] Gomes, J.F.P.S., Rocha, S., Pereira, M. do C., Peres, I., Moreno, S., Toca-Herrera, J. and Coelho, M.A.N. (2010) Lipid/particle Assemblies Based on Maltodextrin-Gum Arabic Core as Bio-Carriers. Colloids and Surfaces B: Biointerfaces, 76, 449-455. http://dx.doi.org/10.1016/j.colsurfb.2009.12.004

[22] Kumari, A., Yadav, S.K., Pakade, Y.B., Singh, B. and Yadav, S.C. (2010) Development of Biodegradable Nanoparticles for Delivery of Quercetin. Colloids and Surfaces B: Biointerfaces, 80, 184-192. http://dx.doi.org/10.1016/j.colsurfb.2010.06.002

[23] Tan, B.-J., Liu, Y., Chang, K.-L., Lim, B.K. and Chiu, G.N. (2012) Perorally Active Nanomicellar Formulation of Quercetin in the Treatment of Lung Cancer. International Journal of Nanomedicine, 7, 651-661.

[24] Zhai, Y., Guo, S., Liu, C., Yang, C., Dou, J., Li, L. and Zhai, G. (2013) Preparation and in Vitro Evaluation of Apigenin-Loaded Polymeric Micelles. Colloids and Surfaces A: Physicochemical and Engineering Aspects, 429, 24-30. http://dx.doi.org/10.1016/j.colsurfa.2013.03.051

[25] Rangel-Yagui, C.O., Pessoa Jr., A. and Tavares, L.C. (2005) Micellar Solubilization of Drugs. Journal of Pharmacy \& Pharmaceutical Sciences, 8, 147-165.

[26] Lasic, D.D. (1992) Mixed Micelles in Drug Delivery. Nature, 355, 279-280. http://dx.doi.org/10.1038/355279a0

[27] Chat, O.A., Najar, M.H., Mir, M.A., Rather, G.M. and Dar, A.A. (2011) Effects of Surfactant Micelles on Solubilization and DPPH Radical Scavenging Activity of Rutin. Journal of Colloid and Interface Science, 355, 140-149. http://dx.doi.org/10.1016/j.jcis.2010.11.044

[28] McClements, D.J. (2012) Nanoemulsions versus Microemulsions: Terminology, Differences, and Similarities. Soft 
Matter, 8, 1719-1729. http://dx.doi.org/10.1039/c2sm06903b

[29] Kang, B.K., Lee, J.S., Chon, S.K., Jeong, S.Y., Yuk, S.H., Khang, G., Lee, H.B. and Cho, S.H. (2004) Development of Self-Microemulsifying Drug Delivery Systems (SMEDDS) for Oral Bioavailability Enhancement of Simvastatin in Beagle Dogs. International Journal of Pharmaceutics, 274, 65-73. http://dx.doi.org/10.1016/j.ijpharm.2003.12.028

[30] Rogerio, A.P., Dora, C.L., Andrade, E.L., Chaves, J.S., Silva, L.F.C., Lemos-Senna, E. and Calixto, J.B. (2010) AntiInflammatory Effect of Quercetin-Loaded Microemulsion in the Airways Allergic Inflammatory Model in Mice. Pharmacological Research, 61, 288-297. http://dx.doi.org/10.1016/j.phrs.2009.10.005

[31] Zhang, Y., Wang, R., Wu, J. and Shen, Q. (2012) Characterization and Evaluation of Self-Microemulsifying SustainedRelease Pellet Formulation of Puerarin for Oral Delivery. International Journal of Pharmaceutics, 427, 337-344. http://dx.doi.org/10.1016/j.ijpharm.2012.02.013

[32] Mekjaruskul, C., Yang, Y.-T., Leed, M.G.D., Sadgrove, M.P., Jay, M. and Sripanidkulchai, B. (2013) Novelformulation Strategies for Enhancing Oral Delivery of Methoxyflavones in Kaempferia parviflora by SMEDDS or Complexation with 2-Hydroxypropyl- $\beta$-Cyclodextrin. International Journal of Pharmaceutics, 445, 1-11. http://dx.doi.org/10.1016/j.ijpharm.2013.01.052

[33] Wu, J.-W., Lin, L.-C., Hung, S.-C., Chi, C.-W. and Tsai, T.-H. (2007) Analysis of Silibinin in Rat Plasma and Bile for Hepatobiliary Excretion and Oral Bioavailability Application. Journal of Pharmaceutical and Biomededical Analysis, 45, 635-641. http://dx.doi.org/10.1016/j.jpba.2007.06.026

[34] Wei, Y., Ye, X., Shang, X., Peng, X., Bao, Q., Liu, M., Guo, M. and Li, F. (2012) Enhanced Oral Bioavailability of Silybin by a Supersaturatable Self-Emulsifying Drug Delivery System (S-SEDDS). Colloids and Surfaces A: Physicochemical and Engineering Aspects, 396, 22-28. http://dx.doi.org/10.1016/j.colsurfa.2011.12.025

[35] Jain, S., Jain, A.K., Pohekar, M. and Thanki, K. (2013) Novel Self-Emulsifying Formulation of Quercetin for Improved in Vivo Antioxidant Potential: Implications for Drug-Induced Cardiotoxicity and Nephrotoxicity. Free Radical Biology \& Medicines, 65, 117-130. http://dx.doi.org/10.1016/j.freeradbiomed.2013.05.041

[36] Liu, W., Tian, R., Hu, W., Jia, Y., Jiang, H., Zhang, J. and Zhang, L. (2012) Preparation and Evaluation of Self-Microemulsifying Drug Delivery System of Baicalein. Fitoterapia, 83, 1532-1539. http://dx.doi.org/10.1016/j.fitote.2012.08.021

[37] Mehnert, W. and Mäder, K. (2001) Solid Lipid Nanoparticles: Production, Characterization and Applications. Advanced Drug Delivery Reviews, 47, 165-196. http://dx.doi.org/10.1016/S0169-409X(01)00105-3

[38] Li, H., Zhao, X., Ma, Y., Zhai, G., Li, L. and Lou, H. (2009) Enhancement of Gastrointestinal Absorption of Quercetin by Solid Lipid Nanoparticles. Journal of Control Release, 133, 238-244. http://dx.doi.org/10.1016/j.jconrel.2008.10.002

[39] Luo, C.-F., Yuan, M., Chen, M.-S., Liu, S.-M., Zhu, L., Huang, B.-Y., Liu, X.-W. and Xiong, W. (2011) Pharmacokinetics, Tissue Distribution and Relative Bioavailability of Puerarin Solid Lipid Nanoparticles Following Oral Administration. International Journal of Pharmaceutics, 410, 138-144. http://dx.doi.org/10.1016/j.ijpharm.2011.02.064

[40] Müller, R.H., Radtke, M. and Wissing, S.A. (2002) Nanostructured Lipid Matrices for Improved Microencapsulation of Drugs. International Journal of Pharmaceutics, 242, 121-128. http://dx.doi.org/10.1016/S0378-5173(02)00180-1

[41] Liu, L., Tang, Y., Gao, C., Li, Y., Chen, S., Xiong, T., Li, J., Du, M., Gong, Z., Chen, H., Liu, L. and Yao, P. (2014) Characterization and Biodistribution in Vivo of Quercetin-Loaded Cationic Nanostructured Lipid Carriers. Colloids and Surfaces B: Biointerfaces, 115, 125-131. http://dx.doi.org/10.1016/j.colsurfb.2013.11.029

[42] Fathi, M., Varshosaz, J., Mohebbi, M. and Shahidi, F. (2013) Hesperetin-Loaded Solid Lipid Nanoparticles and Nanostructure Lipid Carriers for Food Fortification: Preparation, Characterization, and Modeling. Food Bioprocess Technology, 6, 1464-1475. http://dx.doi.org/10.1007/s11947-012-0845-2

[43] Fathi, M. and Varshosaz, J. (2013) Novel Hesperetin Loaded Nanocarriers for Food Fortification: Production and Characterization. Journal of Functional Foods, 5, 1382-1391. http://dx.doi.org/10.1016/j.jff.2013.05.006

[44] Dodziuk, H., Ed. (2006) Cyclodextrins and Their Complexes. Wiley-VCH Verlag GmbH \& Co. KGaA, Weinheim.

[45] Folch-Cano, C., Guerrero, J., Speisky, H., Jullian, C. and Olea-Azar, C. (2013) NMR and Molecular Fluorescence Spectroscopic Study of the Structure and Thermodynamic Parameters of EGCG/ $\beta$-Cyclodextrin Inclusion Complexes with Potential Antioxidant Activity. Journal of Inclusion Phenomena and Macrocyclic Chemistry, 78, 287-298. http://dx.doi.org/10.1007/s10847-013-0297-y

[46] Miyake, K., Arima, H., Hirayama, F., Yamamoto, M., Horikawa, T. and Sumiyoshi, H. (2000) Improvement of Solubility and Oral Bioavailability of Rutin by Complexation with 2-Hydroxypropyl-Beta-Cyclodextrin. Pharmaceutical Development and Technology, 5, 399-407. http://dx.doi.org/10.1081/PDT-100100556

[47] Nguyen, T.A., Liu, B., Zhao, J., Thomas, D.S. and Hook, J.M. (2013) An Investigation into the Supramolecular Structure, Solubility, Stability and Antioxidant Activity of Rutin/Cyclodextrin Inclusion Complex. Food Chemistry, 136, 186-192. http://dx.doi.org/10.1016/j.foodchem.2012.07.104 
[48] Chakraborty, S., Basu, S., Lahiri, A. and Basak, S. (2010) Inclusion of Chrysin in $\beta$-Cyclodextrin Nanocavity and Its Effect on Antioxidant Potential of Chrysin: A Spectroscopic and Molecular Modeling Approach. Journal of Molecular Structure, 977, 180-188. http://dx.doi.org/10.1016/j.molstruc.2010.05.030

[49] Calabrò, M.L., Tommasini, S., Donato, P., Raneri, D., Stancanelli, R. and Ficarra, P. (2004) Effects of Alpha- and Beta-Cyclodextrin Complexationon the Physico-Chemical Properties and Antioxidant Activity of Some 3-Hydroxyflavones. Journal of Pharmaceutical and Biomedical Analysis, 35, 365-377. http://dx.doi.org/10.1016/j.jpba.2003.12.005

[50] Jullian, C., Moyano, L., Yañez, C. and Olea-Azar, C. (2007) Complexation of Quercetin with Three Kinds of Cyclodextrins: An Antioxidant Study. Spectro-Chimica Acta Part A: Molecular and Biomolecular Spectroscopy, 67, $230-234$. http://dx.doi.org/10.1016/j.saa.2006.07.006

[51] Carlotti, M.E., Sapino, S., Ugazio, E. and Caron, G. (2010) On the Complexation of Quercetin with Methyl- $\beta$-Cyclodextrin: Photostability and Antioxidant Studies. Journal of Inclusion Phenomena and Macrocyclic Chemistry, 70, 8190.

[52] Bergonzi, M.C., Bilia, A.R., Di Bari, L., Mazzi, G. and Vincieri, F.F. (2007) Studies on the Interactions between Some Flavonols and Cyclodextrins. Bioorganic and Medicinal Chemistry Letters, 17, 5744-5748. http://dx.doi.org/10.1016/j.bmcl.2007.08.067

[53] Jullian, C., Brossard, V., Gonzalez, I., Alfaro, M. and Olea-Azar, C. (2011) Cyclodextrins-Kaempferol Inclusion Complexes: Spectroscopic and Reactivity Studies. Journal of Solution Chemistry, 40, 727-739. http://dx.doi.org/10.1007/s10953-011-9674-6

[54] Shulman, M., Cohen, M., Soto-Gutierrez, A., Yagi, H., Wang, H.Y., Goldwasser, J., Lee-Parsons, C.W., Benny-Ratsaby, O., Yarmush, M.L. and Nahmias, Y. (2011) Enhancement of Naringenin Bioavailability by Complexation with Hydroxypropoyl- $\beta$-Cyclodextrin. PLoS ONE, 6, e18033. http://dx.doi.org/10.1371/journal.pone.0018033

[55] Yang, L.-J., Ma, S.-X., Zhou, S.-Y., Chen, W., Yuan, M.-W. and Yin, Y.-Q. (2013) Preparation and Characterization of Inclusion Complexes of Naringeninwith $\beta$-Cyclodextrin or Its Derivative. Carbohydrate Polymers, 98, 861-869. http://dx.doi.org/10.1016/j.carbpol.2013.07.010

[56] Tommasini, S., Calabrò, M.L., Stancanelli, R., Donato, P., Costa, C., Catania, S., Villari, V., Ficarra, P. and Ficarra, R. (2005) The Inclusion Complexes of Hesperetin and Its 7-Rhamnoglucoside with (2-Hydroxypropyl)-Beta-Cyclodextrin. Journal of Pharmaceutical and Biomedical Analysis, 39, 572-580. http://dx.doi.org/10.1016/j.jpba.2005.05.009

[57] Ficarra, R., Tommasini, S., Raneri, D., Calabrò, M., Di Bella, M. and Rustichelli, C. (2002) Study of Flavonoids/ $\beta$ Cyclodextrins Inclusion Complexes by NMR, FT-IR, DSC, X-Ray Investigation. Journal of Pharmaceutical and Biomedical Analysis, 29, 1005-1014. http://dx.doi.org/10.1016/S0731-7085(02)00141-3

[58] Yang, L.-J., Chen, W., Ma, S.-X., Gao, Y.-T., Huang, R., Yan, S.-J. and Lin, J. (2011) Host-Guest System of Taxifolin and Native Cyclodextrin or Its Derivative: Preparation, Characterization, Inclusion Mode, and Solubilisation. Carbohydrate Polymers, 85, 629-637. http://dx.doi.org/10.1016/j.carbpol.2011.03.029

[59] Daruházi, A.E., Kiss, T., Vecsernyés, M., Szente, L., Szőke, E. and Lem-berkovics, E. (2013) Investigation of Transport of Genistein, Daidzein and Their Inclusion Complexes Prepared with Different Cyclodextrins on Caco-2 Cell Line,” Journal of Pharmaceutical and Biomedical Analysis, 84C, 112-116. http://dx.doi.org/10.1016/j.jpba.2013.05.012

[60] Yatsu, F.K.J., Koester, L.S., Lula, I., Passos, J.J., Sinisterra, R. and Bassani, V.L. (2013) Multiple Complexation of Cyclodextrin with Soy Isoflavones Present in an Enriched Fraction. Carbohydrate Polymers, 98, 726-735. http://dx.doi.org/10.1016/j.carbpol.2013.06.062

[61] Fricker, G., Kromp, T., Wendel, A., Blume, A., Zirkel, J., Rebmann, H., Setzer, C., Quinkert, R.O., Martin, F. and Muller-Goymann, C. (2010) Phospholipids and Lipid-Based Formulations in Oral Drug Delivery. Pharmaceutical Research, 27, 1469-1486. http://dx.doi.org/10.1007/s11095-010-0130-x

[62] Sharma, S. and Roy, R.K. (2010) Phytosomes: An Emerging Technology. International Journal of Pharmaceutical Research and Development, 2, 1-5.

[63] Chen, Z.P., Sun, J., Chen, H.X., Xiao, Y.Y., Liu, D., Chen, J., Cai, H. and Cai, B.C. (2010) Comparative Pharmacokinetics and Bioavailability Studies of Quercetin, Kaempferol and Isorhamnetin after Oral Administration of Ginkgo biloba Extracts, Ginkgo biloba Extract Phospholipid Complexes and Ginkgo biloba Extract Solid Dispersions in Rats. Fitoterapia, 81, 1045-1052. http://dx.doi.org/10.1016/j.fitote.2010.06.028

[64] Bombardelli, E., Gabetta, B. and Pifferi, G. (1988) Complexes of Flavanolignanes with Phospholipids, Preparation Thereof and Associated Pharmaceutical Compositions. EP0209038 B1.

[65] Song, Y., Zhuang, J., Guo, J., Xiao, Y. and Ping, Q. (2008) Preparation and Properties of a Silybin-Phospholipid Complex. Pharmazie, 63, 35-42.

[66] Pietta, P., Simonetti, P., Gardana, C., Brusamolino, A., Morazzoni, P. and Bombardelli, E. (1998) Relationship be- 
tween Rate and Extent of Catechin Absorption and Plasma Antioxidant Status. Biochemical and Molecular Biology International, 46, 895-903.

[67] Singh, D., Rawat, M.S.M., Semalty, A. and Semalty, M. (2012) Quercetin-Phospholipid Complex: An Amorphous Pharmaceutical System in Herbal Drug Delivery. Current Drug Discovery Technologies, 9, 17-24.

http://dx.doi.org/10.2174/157016312799304507 
Scientific Research Publishing (SCIRP) is one of the largest Open Access journal publishers. It is currently publishing more than 200 open access, online, peer-reviewed journals covering a wide range of academic disciplines. SCIRP serves the worldwide academic communities and contributes to the progress and application of science with its publication.

Other selected journals from SCIRP are listed as below. Submit your manuscript to us via either submit@scirp.org or Online Submission Portal.
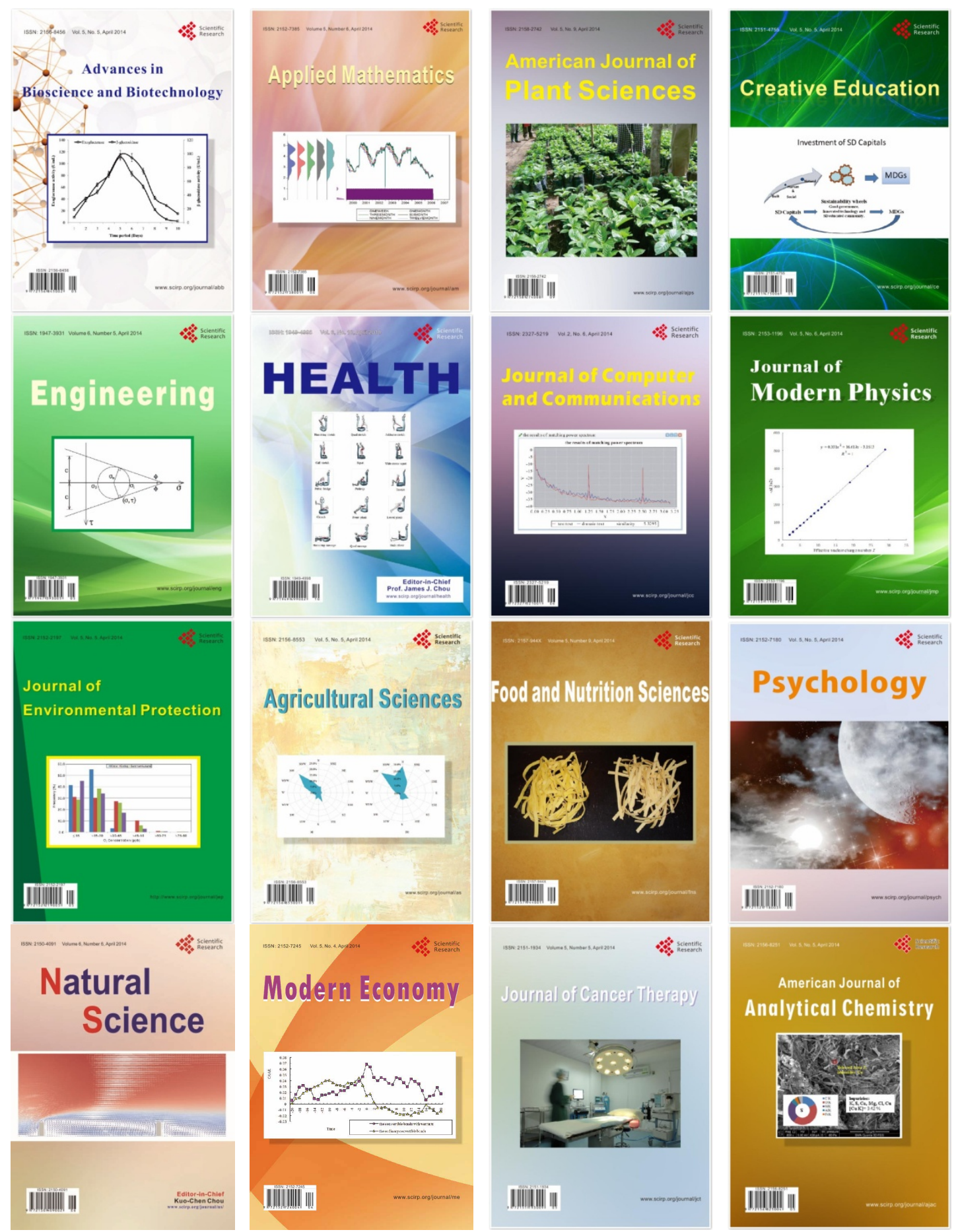